\title{
Mg diffusion and activation along threading dislocations in GaN
}

Cite as: Appl. Phys. Lett. 116, 242103 (2020); https://doi.org/10.1063/5.0009596

Submitted: 03 April 2020. Accepted: 05 June 2020. Published Online: 16 June 2020

Wei Yi (D), Ashutosh Kumar (D), Jun Uzuhashi (D), Takashi Kimura, Ryo Tanaka (D), Shinya Takashima (D), Masaharu Edo, Yongzhao Yao (D), Yukari Ishikawa (D), Jun Chen (D), Tadakatsu Ohkubo (D), Takashi Sekiguchi, and Kazuhiro Hono (iD)
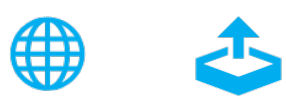

\section{Lock-in Amplifiers up to $600 \mathrm{MHz}$}
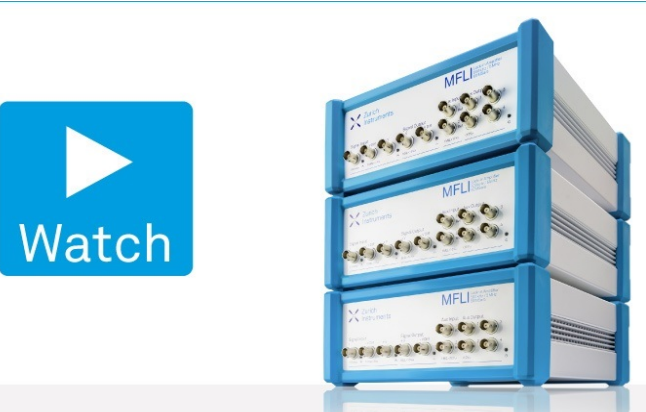


\title{
Mg diffusion and activation along threading dislocations in GaN
}

\author{
Cite as: Appl. Phys. Lett. 116, 242103 (2020); doi: 10.1063/5.0009596 \\ Submitted: 3 April 2020 - Accepted: 5 June 2020 • \\ Published Online: 16 June 2020
}

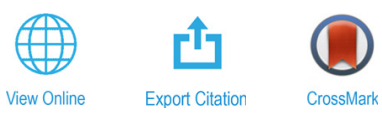

Wei Yi, ${ }^{1}$ (D) Ashutosh Kumar,, ${ }^{1, a)}$ (iD Jun Uzuhashi, ${ }^{1}$ (D) Takashi Kimura, ${ }^{7}$ Ryo Tanaka, ${ }^{2}$ (D) Shinya Takashima, ${ }^{2}$ Masaharu Edo, ${ }^{2}$ Yongzhao Yao, ${ }^{3}$ (iD Yukari Ishikawa, ${ }^{3}$ (D) Jun Chen, ${ }^{7, a)}$ (iD Tadakatsu Ohkubo, Takashi Sekiguchi, ${ }^{1,4}$ and Kazuhiro Hono ${ }^{1}$

\author{
AFFILIATIONS \\ ${ }^{7}$ National Institute for Materials Science, Tsukuba 305-0047, Japan \\ ${ }^{2}$ Advanced Technology Laboratory, Fuji Electric Co. Ltd., Hino, Tokyo 191-8502, Japan \\ 3Japan Fine Ceramics Center, 2-4-1 Mutsuno, Atsuta, Nagoya 456-8587, Japan \\ ${ }^{4}$ University of Tsukuba, Tsukuba 305-8577, Japan
}

${ }^{a)}$ Authors to whom correspondence should be addressed: Kumar.Ashutosh@nims.go.jp and Chen.jun@nims.go.jp

\begin{abstract}
The precise control of $p$-GaN is a crucial issue for developing GaN-based power devices. $\mathrm{Mg}$ as an acceptor is commonly used in $p$-type doping; however, the Mg diffusion through threading dislocations (TDs) has not been well addressed. To clarify the Mg diffusion and activation along TDs, we have performed a systematic characterization of a Mg-implanted homoepitaxial GaN layer grown on a freestanding substrate. Active-Mg related donor-acceptor pair (DAP) emission from certain TDs is identified by cathodoluminescence (CL). Dislocations with and without DAP emission are investigated structurally and compositionally based on etch pits, transmission electron microscopy, and atom-probe tomography. Direct evidence of Mg distribution around edge- and mixed-type TDs is obtained. There exists a significant difference in the Mg concentration and incorporation states between different types of TDs.
\end{abstract}

Published under license by AIP Publishing. https://doi.org/10.1063/5.0009596

As a direct wide-bandgap $(3.47 \mathrm{eV})$ semiconductor, $\mathrm{GaN}$ has been commonly used for optoelectronic device applications, such as light-emitting and laser diodes. ${ }^{1}$ Owing to the merits of high electron mobility, high breakdown electric field, and fast saturation electron velocity, GaN has also attracted great attention as a promising candidate for power semiconductor devices. ${ }^{2-5}$ However, the development of these applications is restricted by two challenging issues: the threading dislocation density (TDD) and the difficulty in precise control of p-type conductivity. Threading dislocations (TDs) are considered as pathways of current leakage, ${ }^{6,7}$ which suppress the critical breakdown electric field and degrade the reliability of devices. ${ }^{8,9}$ In addition, the deep-gap states of dislocations act as nonradiative recombination centers. ${ }^{10}$ Electrostatic and elastic strain fields of dislocations trap alloying elements and impurities, resulting in scattering carriers and reduction of mobility. ${ }^{11,12}$ Thus, the presence of TDs in the $p$ - $n$ junction may be harmful and their impact should be clarified.

A $p$ - $n$ junction is an important component in GaN power devices. The achievement in precise control of $p$-type conductivity is considered as a crucial issue for applications. $\mathrm{Mg}$ has been proven to be the most efficient $p$-type dopant, which is commonly used in
p-GaN fabrication by metal-organic vapor phase epitaxy (MOVPE) growth or via an ion implantation method. The $\mathrm{Mg}$ ion implantation is an important technique for realizing precise doping in both vertical and lateral devices. ${ }^{13-15}$ At room temperature, most implanted $\mathrm{Mg}$ ions are interstitially dissolved without electrical activation. As an acceptor impurity in $\mathrm{GaN}, \mathrm{Mg}$ must be doped in the substitutional Ga site. ${ }^{16}$ Therefore, high temperature post-implantation annealing is essential for promoting $\mathrm{Mg}$ substitution, thus increasing the electrical activation. ${ }^{17-21}$ However, the thermal treatment also induces $\mathrm{Mg}$ diffusion and segregation. ${ }^{22,23}$

In order to achieve reasonable $p$-type conductivity with free hole concentrations up to $10^{18} \mathrm{~cm}^{-3}$, a large dosage of $\mathrm{Mg}$ implantation is required. However, when the $\mathrm{Mg}$ concentration is around $10^{19} \mathrm{~cm}^{-3}$ or more, the $p$-type conductivity is unexpectedly suppressed. The formation of vacancy clusters and various defects associated with the $\mathrm{Mg}$ clusters was reported as the possible reasons for the conductivity suppression. ${ }^{24-26}$ They act as a nonradiative center, resulting in the decrease in the emission intensity of the donor-acceptor pair (DAP) as characterized by photoluminescence of the $\mathrm{Mg}$-implanted (Mg-imp) layer. ${ }^{27,28}$ Recently, we carried out high resolution 
cathodoluminescence (CL) imaging on the slanted cross section of the $p-n$ junction prepared by the angle cutting method, in which DAP emission from certain TDs beneath the Mg-imp layer was found. ${ }^{29}$ This suggests the existence of Mg diffusion along certain TDs and the high rate of $\mathrm{Mg}$ activation. Meanwhile, using the atom probe study, Usami et al. have confirmed the Mg diffusion through mixed-type threading dislocations without causing the leakage in the $n$-GaN layer beneath $p$-GaN grown by MOVPE. ${ }^{30}$

The controversy arises due to a lack of full understanding of the interaction between TDs and Mg. There are a variety of TDs in the GaN epilayer, and they are structurally classified into three categories: edge-type with a Burgers vector of $\boldsymbol{b}=1 / 3\langle 11-20\rangle$, screw-type with $\boldsymbol{b}$ $=\langle 0001\rangle$, and mixed-type $\boldsymbol{b}=1 / 3\langle 11-23\rangle$ with both $\langle\boldsymbol{a}\rangle$ and $\langle\boldsymbol{c}\rangle$ components. ${ }^{31}$ Depending on the character of dislocations, their impact on $\mathrm{Mg}$ diffusion and activation may be different. Hence, it is necessary to clarify the $\mathrm{Mg}$ diffusion via different TDs and to distinguish which kind of TD tends to be electrically active with activated Mg. In this work, we have carried out a comprehensive study on the interaction between TDs and $\mathrm{Mg}$ in the Mg-imp homoepitaxial GaN layer. It includes optical characterization by CL focusing on the distribution of activated $\mathrm{Mg}$, structural analysis of dislocation character based on the etch pit and transmission electron microscope (TEM), and atomic distribution of $\mathrm{Mg}$ at different dislocations by atom probe tomography (APT).

Figure 1 shows the experimental procedure in this study. As shown in Fig. 1(a), the substrate is $c$-plane free standing GaN (sub-GaN) grown by the hydride vapor-phase epitaxy (HVPE) method, with an $n$-type (Si doped) carrier concentration of around $1.75 \times 10^{18} \mathrm{~cm}^{-3}$ and a threading dislocation density of around $10^{6} \mathrm{~cm}^{-2}$. A $10 \mu \mathrm{m}$ thick homoepitaxial $n$-GaN layer (epi-GaN) was grown by MOVPE with a carrier concentration around $1.5 \times 10^{16} \mathrm{~cm}^{-3}$ by $\mathrm{Si}$ doping. $\mathrm{Mg}$ ions are implanted into the epi-GaN layer surface at room temperature by

(a) Mg-implantation
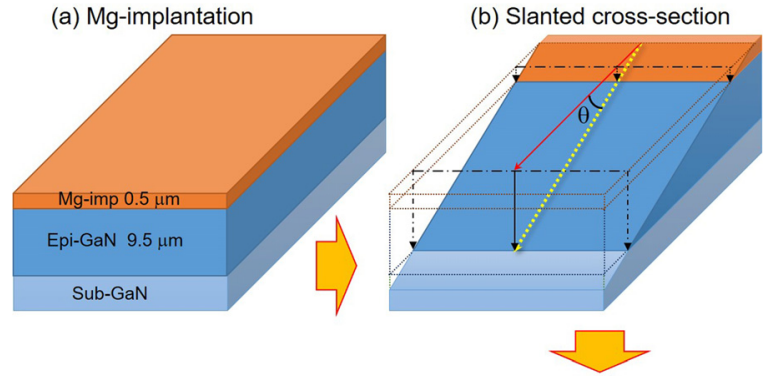

(d) TEM observation

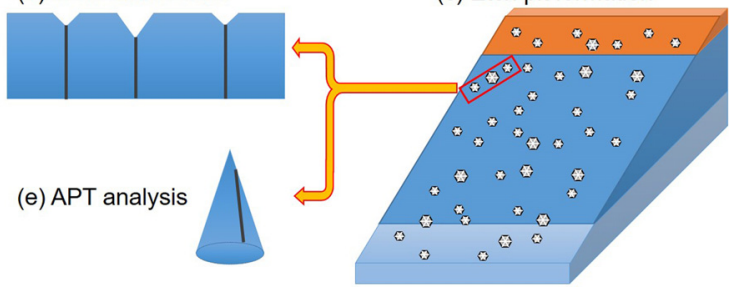

FIG. 1. Characterization sequence: (a) Schematic structure of Mg implanted epi$\mathrm{GaN}$, (b) CL characterization performed on the slanted cross section, (c) etch pit formation using molten $\mathrm{KOH}$, (d) FIB vertical cross-sectional specimen for TEM observation, and (e) needle specimen with the TD for APT analysis. multiple energies to form a $500 \mathrm{~nm}$ thick box profile, with a $\mathrm{Mg}$ concentration of $1 \times 10^{19} \mathrm{~cm}^{-3}$. Then, post annealing was performed at $1300^{\circ} \mathrm{C}$ for $5 \mathrm{~min}$ with an AlN protection layer, which is chemically removed after the thermal treatment.

To enhance the spatially resolved CL characterization in the depth direction, slanted cross section polish with a small angle around $4^{\circ}$ to the $c$-plane surface was performed. As shown in Fig. 1(b), CL characterization is performed along the yellow dotted line in the lateral direction. When the depth increases about $1 \mu \mathrm{m}$, the distance reflected in the CL image along the red line is about $14.3 \mu \mathrm{m}$. In this way, the depth resolution is improved. The details have been described in our previous work. $^{29}$ The angle cutting was performed using a cross section polisher (JEOL SM-09010), which used an Ar ion beam at low beam energy of $4 \mathrm{kV}$ with a shield plate. Using a low energy ion beam, a cross-sectional specimen with less surface damage and degradation in the luminescence property was prepared. CL observations were performed with an e-beam of $3 \mathrm{kV}$ and a specimen temperature of $80 \mathrm{~K}$, using a HORIBA MP32 CL system attached to a Hitachi SU6600 fieldemission scanning electron microscope (FE-SEM).

After CL characterization, the specimen was chemically etched by molten $\mathrm{KOH}$ at $520^{\circ} \mathrm{C}$ for $10 \mathrm{~min}$. The etch-pits were used as makers to confirm locations of dislocations as shown in Fig. 1(c). A dislocation below an etch pit is picked up by the liftout technique using a focus ion beam (FIB). A dual-beam FIB (FEI HeliosG4UX)-based lift-out and annular milling procedure were used to prepare a vertical cross-sectional specimen sheet and needle-shaped specimen for TEM and APT, respectively. In order to avoid gallium implantation and ion-beam damage, a thin protective nickel layer was sputtered on the top of the specimens. The Burgers vector $\boldsymbol{b}$ of the TD was identified based on the $\boldsymbol{g} \cdot \boldsymbol{b}$ analysis in TEM two-beam conditions using a FEI Tecnai G ${ }^{2} 20$ microscope with a double-tilt holder at $200 \mathrm{kV}$. The three-dimensional (3D) atomic distribution of $\mathrm{Mg}$ around a dislocation is obtained by a local electrode atom probe (CAMECA LEAP5000XS) using a laser energy of $10 \mathrm{fJ}$, a detection rate of $1.0 \%$, a temperature of $30 \mathrm{~K}$, and a pulse rate of $250 \mathrm{kHz}$.

Figure 2 shows the CL and secondary electron (SE) images from the top view. Monochromatic CL images taken at donor-acceptor pair (DAP) emission of $3.28 \mathrm{eV}$ and near band edge (NBE) emission of $3.47 \mathrm{eV}$ are shown in Figs. 2(a) and 2(b), respectively. The depth scale is shown by the left axis. In the Mg-imp layer, both DAP and NBE emissions are weak because nonradiative centers such as vacancy-type defects and Mg-clusters are formed by the $\mathrm{Mg}$ implantation of $10^{19} \mathrm{~cm}^{-3}$ and subsequent annealing at $1300^{\circ} \mathrm{C} .{ }^{23,25}$ Under the Mg-imp layer, a bright zone exists in the DAP image due to less implantation damage and few nonradiative defects. ${ }^{29}$ The high intensity of DAP emission suggests that the ratio of $\mathrm{Mg}$ activated as acceptors to nonradiative defects is high in this Mg-activation layer (Mg-act), where the depth is around $700 \mathrm{~nm}$. Beneath this layer, the $n$-type GaN epi-layer is observed as a dark area with bright spots in the DAP image [Fig. 2(a)] and as a bright area with dark spots in the NBE image [Fig. 2(b)]. These dark spots in the NBE image are attributed to TDs, which are considered as a non-irradiative recombination center. However, certain TDs are observed with bright contrast in the DAP image, especially in the region near the Mg-act layer. The number of bright TDs decreases as the depth increases until all TDs are dark where the depth is over $8 \mu \mathrm{m}$. 


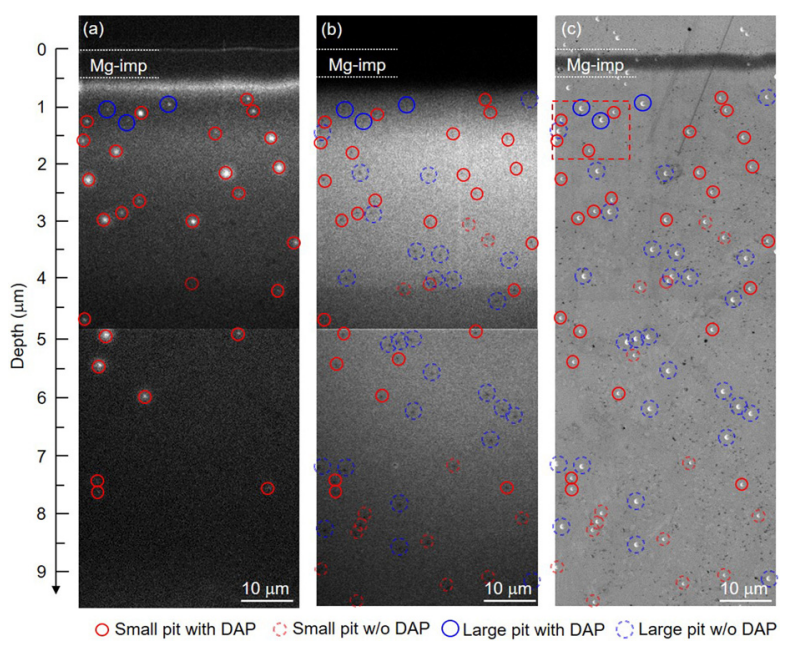

FIG. 2. Monochromatic CL images taken at (a) DAP emission energy and (b) NBE emission energy. (c) SE image of etch-pits in the corresponding region.

Figure 2(c) shows the SE image of the slanted cross section after chemical etching observed from the same region in the DAP and NBE images. The number and location of etch-pits in the epi-layer are consistent with the TDs observed as dark spots in the NBE image. The etch pits are classified into two types, namely, small and large pit according to the size. With the consideration of optical behaviors, the etch pits could be further classified into four categories: small pit with a DAP (solid red circle); small pit without a DAP (dashed red circle); large pit with a DAP (solid blue circle); and large pit without a DAP (dashed blue circle). In Fig. 2(a), the TDs with DAP emission are marked by solid red or blue circles. Except for a few large pits near the Mg-imp layer, almost all the etch pits of TDs with DAP emission are the small pits. The DAP emission at TDs is attributed to Mg diffusion along dislocations. When the depth increases to the deeper region $(>3 \mu \mathrm{m})$, some of the small pits are not visible in the DAP image. The reasons are probably due to $\mathrm{Mg}$ diffusion decay along the depth direction, termination by steps on threading dislocation or basal plane dislocations.

Figures 3(a) and 3(b) show magnified SE images of small and large pits. The diameters of the small and large pits are around 0.7 and $1.1 \mu \mathrm{m}$, respectively. The distorted hexagon of the etch-pits is attributed to the slanted cross-sectional off-angle to the surface. Figure 3(c) shows a histogram of the etch pit size. There are mainly two groups, i.e., small pits with an average diameter of $0.75 \mu \mathrm{m}$ and large pits with an average diameter of $1.05 \mu \mathrm{m}$. The ratio between small and large pits is around 3:2. The total density of etch pits is about $2.6 \times 10^{6} \mathrm{~cm}^{-2}$, corresponding to the density of TDs. The type of TD can be characterized by wet chemical etching. Generally, the etch pits of edge-type dislocations are smaller compared to those for screw and mixed-types. To further confirm the dislocation character, we have picked up typical etch pits by FIB and performed TEM analysis. Figure 3(d) shows an enlarged SE image of the region marked by the dashed red rectangle in Fig. 2(c). Two small pits with obvious DAP emission and one large pit without DAP emission are chosen as denoted in Fig. 3(d).

The TD types below these etch pits are identified on the basis of the invisibility criterion for $\boldsymbol{g} \cdot \boldsymbol{b}=0$, where $\boldsymbol{g}$ is the reciprocal lattice
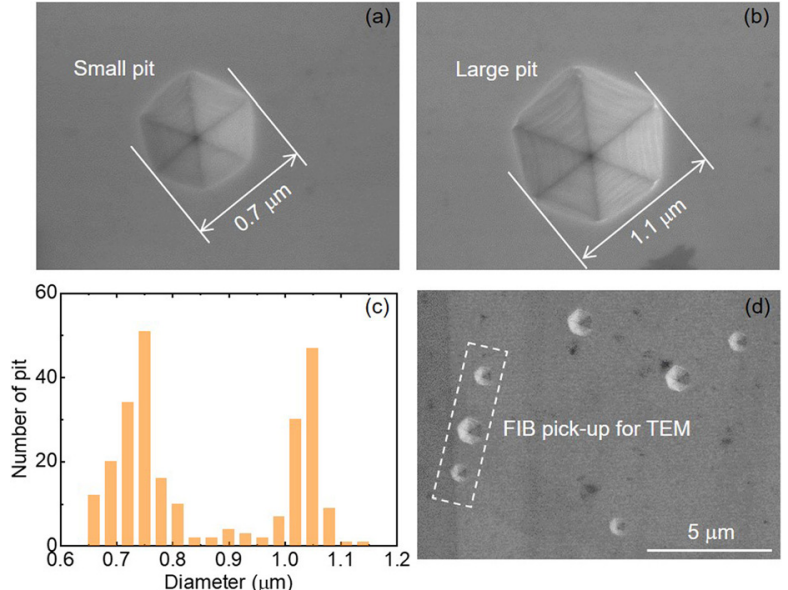

FIG. 3. Magnified SE images of small pit (a) and large pit (b). (c) Histogram of etch pit size. (d) Typical pits selected for FIB and TEM observation.

vector and $\boldsymbol{b}$ is the Burgers vector of the TD, by cross-sectional TEM observation. Figure 4 shows the bright field TEM images of the three TDs, two small pits on both sides and one large pit in the middle, under $g=11-20$ and 0002 diffraction conditions. For small pits, the dislocation lines are visible in the image taken with $g=11-20$, but invisible when $g=0002$, indicating that the small pits are formed on the edge-type TDs (e-TDs). On the other hand, the dislocation line under the large pit is visible in the images with either $11-20$ or 0002 diffraction conditions. Therefore, the large pit is formed on a mixedtype TD (m-TD).

Based on the CL, etch pit, and above TEM results, we can conclude that the edge-type TD tends to be radiative with strong DAP emission, while the mixed-type TD is not obvious. This indicates that the diffusion and activation of $\mathrm{Mg}$ may be different depending on the
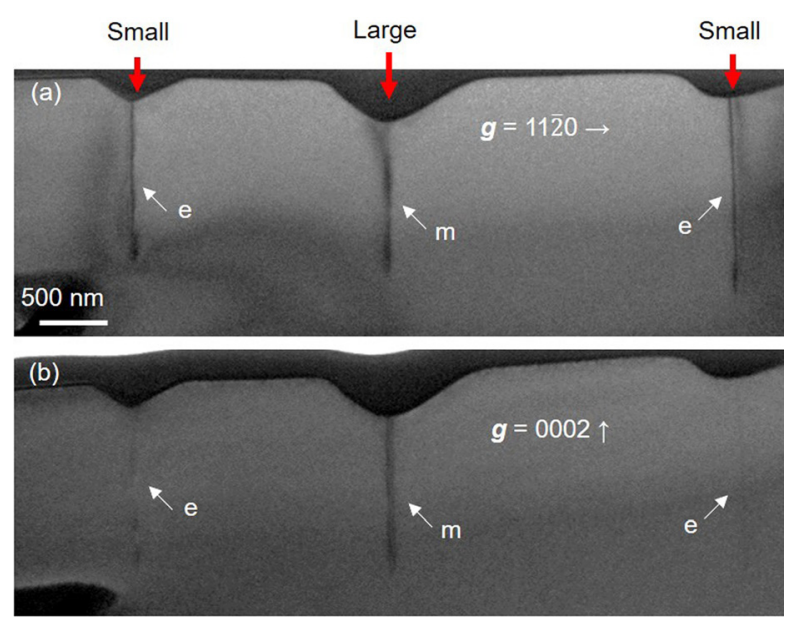

FIG. 4. Bright field TEM images of dislocations below small and large pits taken with the diffraction $g$ of 11-20 and 0002. The small pits are formed on e-TDs, and the large pit is on the m-TD. Segments $m$ and $e$ indicate the m-TDs and e-TDs, respectively. 
TD type. To obtain direct evidence for Mg diffusion along TDs and demonstrate the atomic distribution of $\mathrm{Mg}$ around TDs, APT analyses have been carried out. Two needle specimens containing different types of TDs were fabricated by FIB. Figure 5(a) shows the volumerendered 3D-map of $\mathrm{Mg}$ distribution obtained by APT. The needle specimen contains a mixed-type TD under the nonradiative large pit, which is in the middle of Fig. 4. The relative concentration of $\mathrm{Mg}$ is shown by the color scale. It clearly demonstrates that $\mathrm{Mg}$ strongly segregated along the mixed-type TD. It is noted that only the top segment of the needle specimen contains dislocation due to the angle between the mixed-type TD and the central axis of the needle.

Figure 5(b) shows a Mg-concentration profile crossing the mixed-type TD calculated from the cylindrical volume in Fig. 5(a). The location of the investigation region is around $2 \mu \mathrm{m}$ deep. The cylinder is $15 \mathrm{~nm}$ in diameter and $50 \mathrm{~nm}$ in length. The top project view of $\mathrm{Mg}$ distribution around the mixed-type TD is shown in the inset of Fig. 5(b). The rectangle in dotted lines shown in the inset of Fig. 5(b) corresponding to the cylindrical sketch shown in Fig. 5(a) indicates the location of the region, in which the $\mathrm{Mg}$ concentration profile is investigated. The background Mg-concentration is around 0.015 at. \% and the peak concentration is about 1.3 at. \%, where the core of the mixed-type TD is located. This indicates that $\mathrm{Mg}$ is segregated at the mixed-type TD, in agreement with recent work in $p-\mathrm{GaN}$ grown by MOVPE.

For comparison, the needle specimen containing an edge-type TD with DAP emission is also investigated. Figure 5(c) shows the volume-rendered 3D image of $\mathrm{Mg}$ distribution in the needle specimen, in which no obvious enrichment of $\mathrm{Mg}$ can be found. From the top project view, as shown in the inset of Fig. 5(d), slight enrichment of

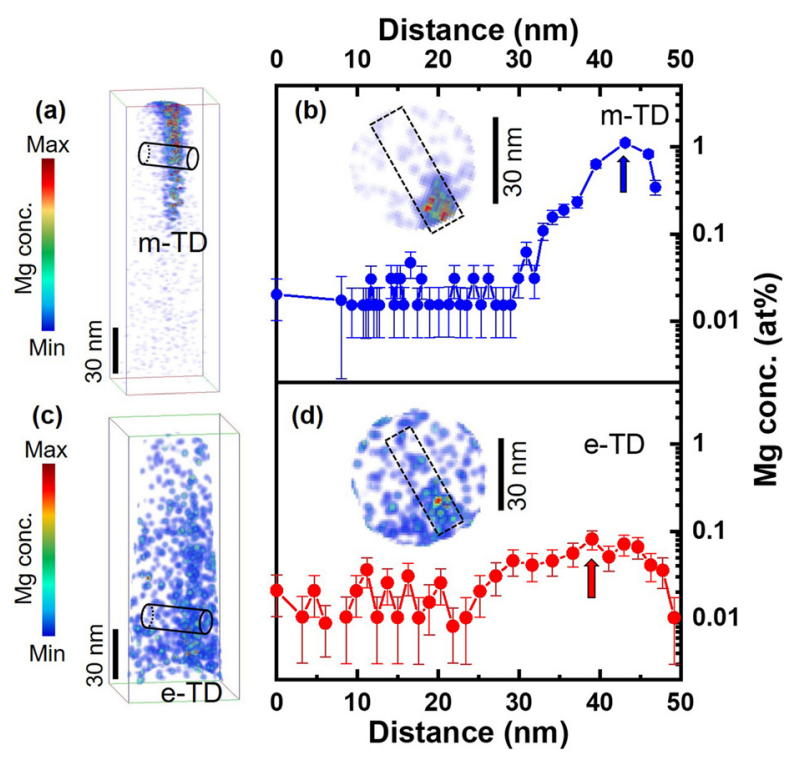

FIG. 5. APT analysis of Mg distribution around different TDs. (a) Volume-rendered 3D image of Mg distribution and (b) Mg concentration profile around the $\mathrm{m}-\mathrm{TD}$; (c) volume-rendered $3 \mathrm{D}$ image of $\mathrm{Mg}$ distribution and (d) $\mathrm{Mg}$ concentration profile around the e-TD. The cylindrical sketches in (a) and (c) show the Mg concentration profile investigating regions. The inset images in (b) and (d) show the XY plane projection view of $\mathrm{Mg}$ distribution.
Mg can be observed around the edge-type TD. Figure 5(d) shows the $\mathrm{Mg}$-concentration profile crossing the edge-type TD. The Mg concentrations are around 0.08 at. $\%$ at the peak position and 0.015 at. $\%$ at the background, indicating that the $\mathrm{Mg}$ concentration along the radiative edge-type TD is much lower compared to that of the nonradiative mixed-type TD.

Now, it is clarified that the diffusion of $\mathrm{Mg}$ is enhanced through not only mixed-type but also the edge-type TD since a relatively high $\mathrm{Mg}$-concentration is detected around TDs in the $n$-type GaN epi-layer. A dislocation pipe diffusion model has been proposed in a previous study. ${ }^{29}$ For the epi-layer about $2-3 \mu \mathrm{m}$ deep beneath the surface, the $\mathrm{Mg}$ concentration in the matrix is less than $1 \times 10^{16} \mathrm{~cm}^{-3}$, which is much lower than the atom probe detection limit $\left(\sim 1 \times 10^{18} \mathrm{~cm}^{-3}\right)$. However, $\mathrm{Mg}$ is still detected with an enhanced concentration from TDs and its surrounding area in such a deep region. Hence, there exists dislocation pipe diffusion.

The concentration of $\mathrm{Mg}$ in the dislocation core is largely different depending on the type. This is probably due to the variation in the $\mathrm{Mg}$ diffusion and segregation related to the dislocation structure. Considering the Burgers vector of TDs, the edge-type has only the a-component with lattice distortion mainly within the basal plane (c-plane), while the mixed-type has an additional $c$-component with lattice distortion along the $c$-axis. The high concentration of $\mathrm{Mg}$ detected by the atom probe around the mixed-type TD indicates that the mixed-type TD could act as a strong gettering site of $\mathrm{Mg}$. When the $\mathrm{Mg}$ concentration exceeds its solubility limit, strong segregation of $\mathrm{Mg}$ at dislocations is expected to occur. Unlike the edge-type TD, the mixed-type TD is nonradiative because of the high concentration of $\mathrm{Mg}$ segregated at the mixed-type TD, and dopant activation becomes ineffective.

Another consideration is the lateral diffusion of $\mathrm{Mg}$ from the dislocation core to its surrounding area. In the NBE image in Fig. 2(b), all TDs are observed as small dark spots. In the DAP image in Fig. 2(a), however, the bright contrast of edge-type TDs is not uniform, and some brighter one spreads over a wide region from the dislocation core. The size of the bright/dark spot is affected by the e-beam energy (electron range), carrier diffusion length, and distribution of recombination centers. In this study, the electron range is about $100 \mathrm{~nm}$ at $3 \mathrm{kV}$ and the carrier diffusion length is around $60 \sim 70 \mathrm{~nm}$ of the epilayer. High spatial resolution spectra line scan across one bright edge-type TD has been performed. The full width at half maximum (FWHM) of bright contrast in DAP and dark contrast in NBE is about 450 and $200 \mathrm{~nm}$, respectively. These suggest that nonradiative centers are limited to the dislocation core, while Mg-related DAP emission has spread from the dislocation core to its surrounding area. Corresponding to atom probe analysis, the $\mathrm{Mg}$ distribution seems to be insignificantly different between the core and surrounding area of the edge-type TD. It is considered that for the mixed-type TD, the lattice is distorted due to the additional screw component, and the lateral open space that is the diffusion path for $\mathrm{Mg}$ becomes modified, whereas for the edge-type TD, there is no distortion along the $c$-axis and $\mathrm{Mg}$ diffusion is easy through lateral open space.

Therefore, for the mixed-type TD, due to the strong segregation and limited lateral diffusion, most $\mathrm{Mg}$ is in the segregated form; the ratio of activated $\mathrm{Mg}$ is low and DAP emission is not visible due to the presence of numerous nonradiative centers. It is noted that some mixed-type TDs also showed DAP emission as denoted by solid blue 
circles in Fig. 2(a). However, they show much weak DAP emission compared to the edge type. It is considered that these mixed-type TDs in the top region are close to the $\mathrm{Mg}$ activation layer with a high concentration of activated $\mathrm{Mg}$, and although the majority of $\mathrm{Mg}$ segregated at the mixed-type TD, there is still a small amount of activated $\mathrm{Mg}$, while in the deeper region, mixed-type TDs are seldom found with DAP emission. On the other hand, the edge-type TD with DAP occurs even when the depth approaches $7 \mu \mathrm{m}$. The pipe diffusion of $\mathrm{Mg}$ along the TD can be deep into the $n$-type epi-layer about several micrometers, and when TDs are surrounded with a high concentration of activated $\mathrm{Mg}$, dislocations with $p$-type conductivity may act as current shunts and result in device failure. Hence, the edge-type TDs with activated $\mathrm{Mg}$ would be potential threats to the performance of devices. The approaching depth of $\mathrm{Mg}$ diffusion and segregation along the mixed-type TD is unable to be discussed by our CL characterization since without DAP emission. That should be studied in further work, to clarify the effect on device performance.

In summary, the $\mathrm{Mg}$ diffusion and incorporation state around threading dislocations in the Mg-implanted homoepitaxial GaN layer have been clarified based on CL, etch pit, TEM, and APT characterization. Strong DAP emission from edge-type TDs is detected, while mixed-type TDs are nonradiative. Mg diffusion through both types of TDs has been confirmed by APT analysis. But the concentration and incorporation state are different. The high concentration of $\mathrm{Mg}$ is detected from the mixed-type TD and to form Mg segregation. On the other hand, the Mg concentration is slightly enhanced at the edge-type $\mathrm{TD}$, and $\mathrm{Mg}$ diffuses and incorporates on the substitutional Ga site nearby. For the GaN power device, the diffusion of $\mathrm{Mg}$ along TDs should be avoided. Specifically, the negative impact of edge-type TDs with $\mathrm{Mg}$ diffusion and activation should not be underestimated.

\section{AUTHORS' CONTRIBUTIONS}

W.Y., J.C., and T.S. conceptualized this study. W.Y. and J.C. wrote this manuscript. Methodology included: R.T., S.T., and M.E. prepared the $\mathrm{Mg}$ ion implantation; T.K. prepared the angle cutting specimen; W.Y., J.C., and T.S. carried out CL experiments and data analysis; Y.Y. and Y.I. performed the chemical etching; and A.K., J.U., T.O., and K.H. carried out FIB sampling, TEM observation, and APT analysis.

This work was supported by the MEXT "Research and development of next-generation semiconductor to realize energysaving society” Program Grant No. JPJ005357.

\section{DATA AVAILABILITY}

The data that support the findings of this study are available from the corresponding author upon reasonable request.

\section{REFERENCES}

${ }^{1}$ H. Amano, M. Kito, K. Hiramatsu, and I. Akasaki, Jpn. J. Appl. Phys. 28, L2112 (1989).

2J. S. Wang, L. N. Cao, J. Q. Xie, E. Beam, R. McCarthy, C. Youtsey, and P. Fay, Appl. Phys. Lett. 113, 023502 (2018).
${ }^{3}$ K. Nomoto, B. Song, Z. Y. Hu, M. D. Zhu, M. Qi, N. Kaneda, T. Mishima, T. Nakamura, D. Jena, and H. G. Xing, IEEE Electron Device Lett. 37, 161 (2016).

${ }^{4}$ T. J. Flack, B. N. Pushpakaran, and S. B. Bayne, J. Electron. Mater. 45, 2673 (2016).

${ }^{5}$ C. Gupta, Y. Enatsu, G. Gupta, S. Keller, and U. K. Mishra, Phys. Status Solidi A 213, 878 (2016).

${ }^{6}$ J. W. P. Hsu, M. J. Manfra, R. J. Molnar, B. Heying, and J. S. Speck, Appl. Phys. Lett. 81, 79 (2002).

${ }^{7}$ J. J. M. Law, E. T. Yu, G. Koblmuller, F. Wu, and J. S. Speck, Appl. Phys. Lett. 96, $102111(2010)$

${ }^{8}$ M. F. Schubert, S. Chhajed, J. K. Kim, E. F. Schubert, D. D. Koleske, M. H. Crawford, S. R. Lee, A. J. Fischer, G. Thaler, and M. A. Banas, Appl. Phys. Lett. 91, 231114 (2007).

${ }^{9}$ M. Meneghini, N. Trivellin, K. Orita, S. Takigawa, T. Tanaka, D. Ueda, G. Meneghesso, and E. Zanoni, Appl. Phys. Lett. 97, 263501 (2010).

${ }^{10} \mathrm{M}$. Albrecht, J. L. Weyher, B. Lucznik, I. Grzegory, and S. Porowski, Appl. Phys. Lett. 92, 231909 (2008).

${ }^{11}$ D. C. Look and J. R. Sizelove, Phys. Rev. Lett. 82, 1237 (1999).

${ }^{12}$ M. Ťapajna, S. W. Kaun, M. H. Wong, F. Gao, T. Palacios, U. K. Mishra, J. S. Speck, and M. Kuball, Appl. Phys. Lett. 99, 223501 (2011).

${ }^{13}$ J. D. Greenlee, T. J. Anderson, B. N. Feigelson, K. D. Hobart, and F. J. Kub, Phys. Status Solidi A 212, 2772 (2015).

${ }^{14}$ T. Oikawa, Y. Saijo, S. Kato, T. Mishima, and T. Nakamura, Nucl. Instrum. Methods B 365, 168 (2015).

${ }^{15}$ T. Narita, T. Kachi, K. Kataoka, and T. Uesugi, Appl. Phys. Express 10, 016501 (2017).

${ }^{16}$ U. Wahl, L. M. Amorim, V. Augustyns, A. Costa, E. David-Bosne, T. A. L. Lima, G. Lippertz, J. G. Correia, M. R. da Silva, M. J. Kappers, K. Temst, A. Vantomme, and L. M. C. Pereira, Phys. Rev. Lett. 118, 095501 (2017).

${ }^{17}$ B. N. Feigelson, T. J. Anderson, M. Abraham, J. A. Freitas, J. K. Hite, C. R. Eddy, and F. J. Kub, J. Cryst. Growth 350, 21 (2012).

${ }^{18}$ T. J. Anderson, B. N. Feigelson, F. J. Kub, M. J. Tadjer, K. D. Hobart, M. A. Mastro, J. K. Hite, and C. R. Eddy, Jr., Electron. Lett. 50, 197 (2014).

${ }^{19}$ T. J. Anderson, J. D. Greenlee, B. N. Feigelson, J. K. Hite, K. D. Hobart, and F. J. Kub, IEEE Trans. Semicond. Manuf. 29, 343 (2016).

${ }^{20} \mathrm{M}$. Yoshino, K. Sugamata, K. Ikeda, T. Nishimura, K. Kuriyama, and T. Nakamura, Nucl. Instrum. Method Meth. B 449, 49 (2019).

${ }^{21}$ T. Niwa, T. Fujii, and T. Oka, Appl. Phys. Express 10, 091002 (2017).

${ }^{22}$ G. Miceli and A. Pasquarello, Phys. Rev. B. 93, 165207 (2016).

${ }^{23}$ A. Kumar, K. Mitsuishi, T. Hara, K. Kimoto, Y. Irokawa, T. Nabatame, S. Takashima, K. Ueno, M. Edo, and Y. Koide, Nanoscale Res. Lett. 13, 403 (2018).

${ }^{24}$ A. Uedono, H. Iguchi, T. Narita, K. Kataoka, W. Egger, T. Koschine, C. Hugenschmidt, M. Dickmann, K. Shima, K. Kojima, S. F. Chichibu, and S. Ishibashi, Phys. Status Solidi B 256, 1900104 (2019).

${ }^{25}$ A. Uedono, S. Takashima, M. Edo, K. Ueno, H. Matsuyama, W. Egger, T. Koschine, C. Hugenschmidt, M. Dickmann, K. Kojima, S. F. Chichibu, and S. Ishibashi, Phys. Status Solidi B 255, 1700521 (2018).

${ }^{26}$ A. Kumar, J. Uzuhashi, T. Ohkubo, R. Tanaka, S. Takashima, M. Edo, and K. Hono, J. Appl. Phys. 126, 235704 (2019).

${ }^{27}$ M. A. Reshchikov and H. Morkoç, J. Appl. Phys. 97, 061301 (2005).

${ }^{28}$ K. Kojima, S. Takashima, M. Edo, K. Ueno, M. Shimizu, T. Takahashi, S. Ishibashi, A. Uedono, and S. F. Chichibu, Appl. Phys. Express 10, 061002 (2017).

${ }^{29}$ J. Chen, W. Yi, T. Kimura, S. Takashima, M. Edo, and T. Sekiguchi, Appl. Phys. Express 12, 051010 (2019).

${ }^{30}$ S. Usami, N. Mayama, K. Toda, A. Tanaka, M. Deki, S. Nitta, Y. Honda, and H. Amano, Appl. Phys. Lett. 114, 232105 (2019).

${ }^{31}$ J. Elsner, R. Jones, P. K. Sitch, V. D. Porezag, M. Elstner, T. Frauenheim, M. I. Heggie, S. Öberg, and P. R. Briddon, Phys. Rev. Lett. 79, 3672 (1997). 